\title{
CAPACITY INVESTIGATION OF BRINE-BEARING SANDS FOR GEOLOGIC SEQUESTRATION OF $\mathrm{CO}_{2}$
}

\author{
Christine Doughty, Sally M. Benson, and Karsten Pruess \\ Earth Sciences Division \\ Lawrence Berkeley National Laboratory \\ 1 Cyclotron Rd, MS 90-1116 \\ Berkeley, CA 94720
}

\begin{abstract}
The capacity of brine-bearing formations to sequester carbon dioxide $\left(\mathrm{CO}_{2}\right)$ is investigated using mathematical modeling of $\mathrm{CO}_{2}$ injection and storage. $\mathrm{CO}_{2}$ is injected in a supercritical state that has a much lower density and viscosity than the brine it displaces. In situ it forms a gas-like phase, and also partially dissolves in the aqueous phase. The capacity factor is defined as the volume fraction of the subsurface available for $\mathrm{CO}_{2}$ storage and is conceptualized as a product of four factors that account for 1) two-phase flow and transport processes, 2) formation geometry, 3) formation heterogeneity, and 4) formation porosity. The key properties that impact the capacity factor include permeability anisotropy and relative permeability, brine $/ \mathrm{CO}_{2}$ density and viscosity ratios, brine salinity, the shape of trapping structure, formation porosity, and the presence of low-permeability layering. The space and time domains used to define capacity factor must be chosen carefully to obtain meaningful results. Often, there is no unique choice for the volume on which to base the capacity factor. One possible convention is to define a dynamic capacity factor that makes use of the self-similar nature of the Buckley-Leverett solution for the propagation of the $\mathrm{CO}_{2}$ front away from the injection well.
\end{abstract}

\section{INTRODUCTION}

Geologic sequestration of carbon dioxide $\left(\mathrm{CO}_{2}\right)$ in brine-bearing formations has been proposed as a means of reducing the atmospheric load of greenhouse gases. For this procedure to have any meaningful impact on the global carbon cycle, vast quantities of $\mathrm{CO}_{2}$ must be injected into the subsurface and isolated from the biosphere for hundreds or thousands of years. We use numerical simulations to investigate the capacity of deep brine-saturated formations to sequester $\mathrm{CO}_{2}$ that has been compressed to a supercritical state and injected over a 20 -year period. The subsequent 40 -year recovery period after injection ceases is also simulated. The three-dimensional (3D) model includes all flow and transport processes relevant for a twophase (liquid-gas), three-component $\left(\mathrm{CO}_{2}\right.$, water, dissolved $\left.\mathrm{NaCl}\right)$ system [1,2]. In particular, $\mathrm{CO}_{2}$ may exist in a gas-like supercritical state or be dissolved in the aqueous phase. Salt may precipitate out of the brine, but the rock matrix itself is inert. Thus, chemical reactions between $\mathrm{CO}_{2}$ and rock minerals, which can significantly contribute to mineral trapping of $\mathrm{CO}_{2}$ over long time scales [3], are not considered. The 1$\mathrm{km}$ by $1-\mathrm{km}$ by $100-\mathrm{m}$ thick model includes heterogeneity representative of a fluvial geologic setting [4]. Permeability varies by nearly six orders of magnitude, from $7 \cdot 10^{-13} \mathrm{~m}^{2}(700 \mathrm{md})$ sand channels to $10^{-18} \mathrm{~m}^{2}(1$ $\mu \mathrm{d})$ shales, which are arranged in a lenticular fashion, making preferential flow a significant effect as well. 


\section{DEFINITION OF CAPACITY FACTOR}

The capacity factor $C$ is defined as the volume fraction of the subsurface available for $\mathrm{CO}_{2}$ storage and is conceptualized as the product of four factors [5]:

$$
C=C_{\mathrm{i}} C_{\mathrm{g}} C_{\mathrm{h}} \phi
$$

where $C_{\mathrm{i}}$ is the intrinsic capacity, accounting for two-phase flow and transport processes, $C_{\mathrm{g}}$ is a correction for formation geometry, $C_{\mathrm{h}}$ is a correction for formation heterogeneity, and $\phi$ is formation porosity. Moreover, $C_{\mathrm{i}}$ can be divided into gas-phase and liquid-phase contributions:

$$
C_{\mathrm{i}}=C_{\mathrm{ig}}+C_{\mathrm{il}}
$$

where $C_{\mathrm{ig}}=S_{\mathrm{g}}, C_{\mathrm{il}}=S_{1} X_{1}^{\mathrm{CO} 2} \rho_{1} / \rho_{\mathrm{CO} 2}, \mathrm{~S}_{\mathrm{g}}$ and $\mathrm{S}_{1}$ are gas and liquid saturations, respectively, $X_{1}^{\mathrm{CO} 2}$ is $\mathrm{CO}_{2}$ mass fraction in the aqueous phase, and $\rho_{1} / \rho_{\mathrm{CO} 2}$ is the density ratio of brine to $\mathrm{CO}_{2}$ [5]. Buckley-Leverett type analyses enable determination of $C_{\mathrm{ig}}$, considering idealized one-dimensional radial flow geometry $[6,7]$. Numerical simulations are performed to incorporate dissolution of $\mathrm{CO}_{2}$ in the aqueous-phase $\left(C_{\mathrm{il}}\right)$, buoyancy flow $\left(C_{\mathrm{g}}\right)$, geometric effects such as a dipping formation $\left(C_{\mathrm{g}}\right)$, and geologic heterogeneities that control sweep efficiency and bypassing $\left(C_{\mathrm{h}}\right)$. Figure 1 illustrates the different components of the capacity factor.
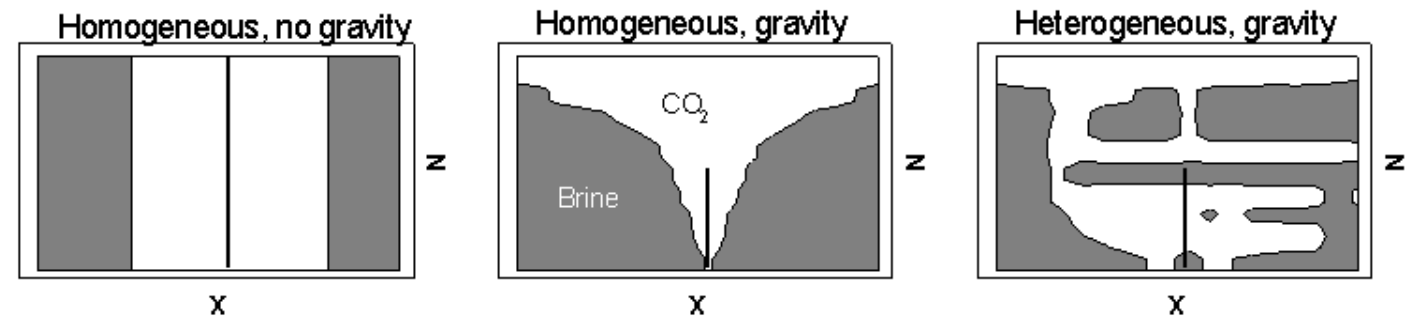

Figure 1. In the left frame, $C_{\mathrm{i}} \phi=\mathrm{C}$, since $C_{\mathrm{g}}=C_{\mathrm{h}}=1$. In the center frame, $C_{\mathrm{g}}<1, C_{\mathrm{h}}=1$. In the right frame, $C_{\mathrm{g}}<1$ and $C_{\mathrm{h}}>1$, since heterogeneity has mitigated buoyancy effects.

Careful consideration of the capacity factor quoted by other authors $[7,8]$ indicates that much of the perceived discrepancies can be attributed to different conventions for defining capacity factor. For example, Pruess et al. [7] use a one-dimensional radial flow model with homogeneous properties and report $C_{\mathrm{i}}$ values in the range of 0.2 to 0.4 . In contrast, van der Meer [8] considers gravity and a dipping formation and applies a rough heterogeneity correction, yielding the much smaller values of $\mathrm{C}_{\mathrm{i}} \mathrm{C}_{\mathrm{g}} \mathrm{C}_{\mathrm{h}}=0.01$ to 0.07 . The difference implies $\mathrm{C}_{\mathrm{g}} \mathrm{C}_{\mathrm{h}} \sim 0.1$, which is near the lower end of the range encountered in our studies.

\section{SIMULATION RESULTS}

The present modeling studies focus on $\mathrm{CO}_{2}$ injection into a sedimentary formation at a depth of $2,000 \mathrm{~m}$ formed by fluvial processes that created strong permeability heterogeneity. The top and bottom boundaries of the model are closed, to represent sealing shale layers, and the lateral boundaries are open, to approximate a laterally extensive formation. $\mathrm{CO}_{2}$ injection takes place at a constant rate through a central well that penetrates the lower half of the 100-m thick model. The simulation shows that $\mathrm{CO}_{2}$ preferentially flows through high-permeability features such as barrier bars, sand channels, splays, and washovers, while avoiding low-permeability flood-plain shale layers (Figure 2). Most shale layers are discontinuous, however, and buoyancy flow is strong, making the interplay between buoyancy flow and formation heterogeneity a key factor in determining the distribution of $\mathrm{CO}_{2}$ in the subsurface, which in turn has important ramifications for the capacity factor. After injection of $\mathrm{CO}_{2}$ ceases, the subsurface distribution of $\mathrm{CO}_{2}$ continues to evolve, primarily driven by buoyancy flow of the gas-like phase out the lateral boundaries of the model. In general, the relative importance of sequestration in the aqueous phase by dissolution can be large if imperfect cap or lateral seals allow the loss of gas-like $\mathrm{CO}_{2}$. 

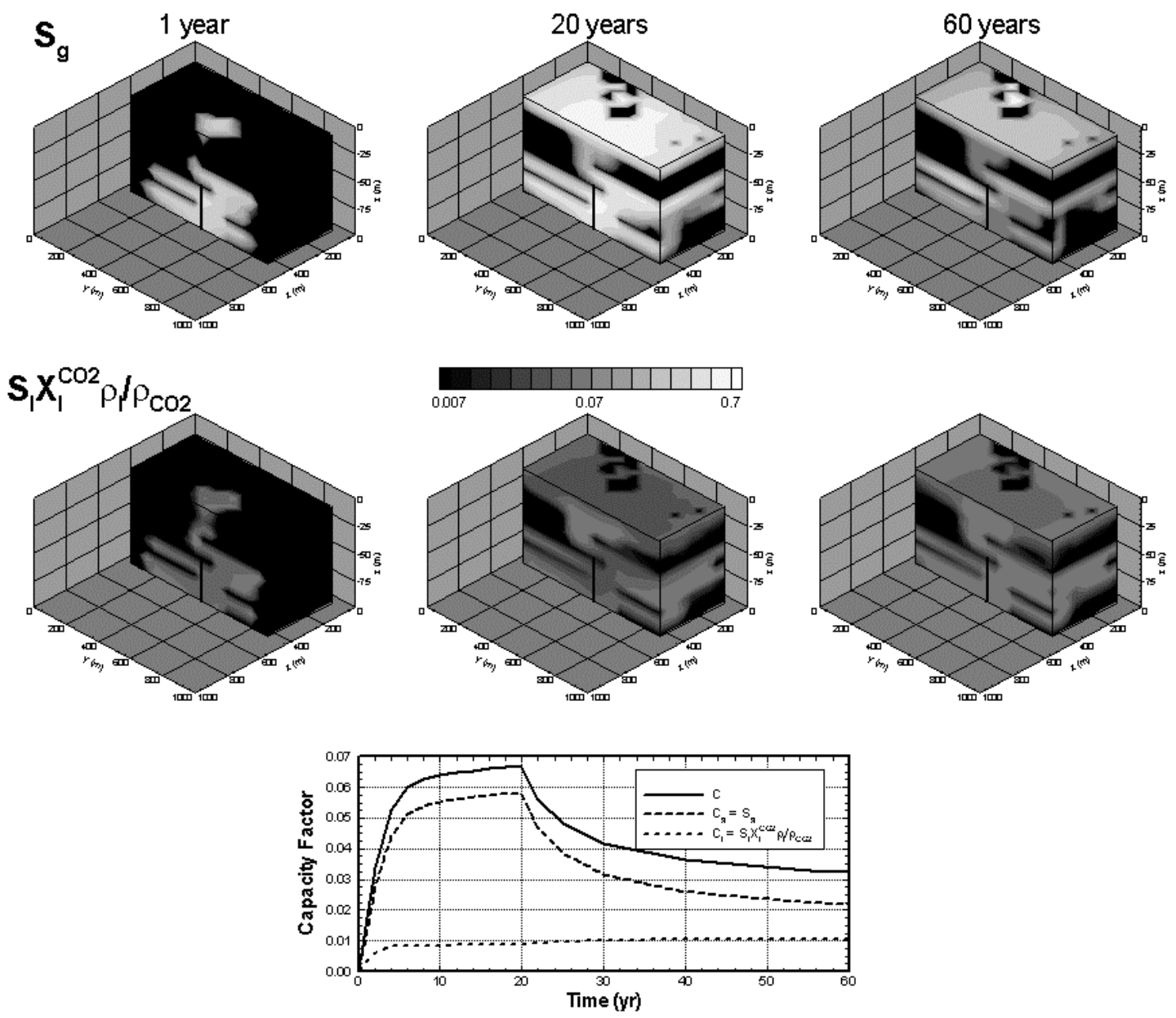

Figure 2. Simulation results for spatial distributions of injected $\mathrm{CO}_{2}$ near the beginning (left column) and end (center column) of the 20 -year injection period, and after a subsequent 40 year recovery period (right column). $\mathrm{CO}_{2}$ exists in a gas-like phase (top row) and dissolved in the aqueous phase (middle row). The capacity factor (bottom row) provides an integrated, quantitative measure of the fraction of the subsurface being used for sequestration.

The space and time domains used to define capacity factor must be chosen carefully to obtain meaningful results. When there is a particular volume associated with the sequestration scenario under consideration (e.g., an isolated fault block, an anticline trapping structure, a volume of the subsurface available to the operator), this is the natural spatial domain to use. In contrast, for a laterally extensive formation with no natural geological boundaries, there is no unique choice for the volume on which to base the capacity factor. In Figure 2, the capacity factor averaging volume is taken to be constant, and to consist of the entire model volume. This choice results in a rapidly increasing $C$ at early times, before $\mathrm{CO}_{2}$ reaches the outer edge of the model, and a gradually decreasing $C$ at late times, after $\mathrm{CO}_{2}$ injection has ceased and buoyant gas-like $\mathrm{CO}_{2}$ escapes out the sides of the model. The strong time dependence of $C$ makes it difficult to choose a single value of $C$ to characterize the sequestration process.

One possible alternative formulation is to define a dynamic capacity factor that makes use of the self-similar nature of the Buckley-Leverett solution for the propagation of the $\mathrm{CO}_{2}$ front away from the injection well. As time $t$ increases, the volume $V$ for which capacity factor is calculated also increases, in accordance with a fixed value of $V / t$. Figure 3 compares $C$ versus $t$ for dynamic (fixed $V / t$ ) and conventional (fixed $V$ ) capacity formulations. In both cases, for the recovery period (20-60 years), $V$ remains fixed at the value used at the end of the injection period. For the $1 \mathrm{~km}$ by $1 \mathrm{~km}$ model, the conventional $C$ versus $t$ curve shares the shortcomings of the $C$ versus $t$ curve shown in Figure 2. For a laterally infinite model, the conventional capacity factor (using the same averaging volume as the finite model) does not characterize the entire $\mathrm{CO}_{2}$ plume, only the central part of it. Choosing a larger averaging volume would delay the time at which the $\mathrm{CO}_{2}$ plume outgrows the averaging volume, but not solve the fundamental problem. In contrast, the dynamic capacity factor characterizes a volume that grows along with the $\mathrm{CO}_{2}$ plume. 


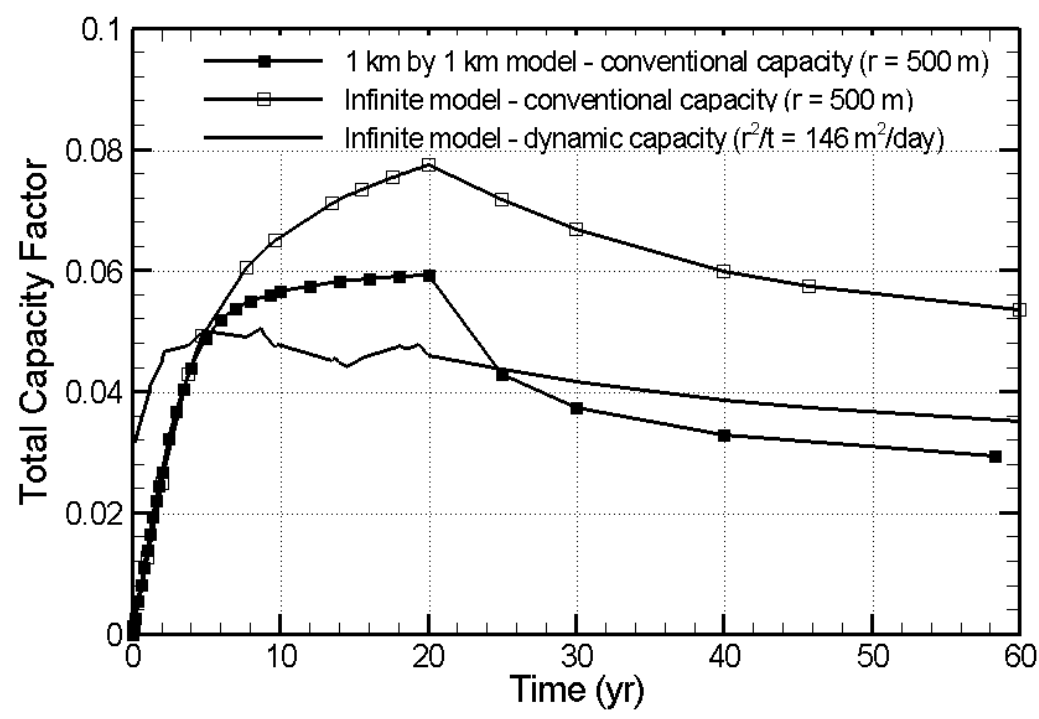

Figure 3. Comparision of dynamic capacity factor, which uses a fixed value of $V / t$ for averaging, and conventional capacity factor, which uses a fixed volume $V$. For these uniform-thickness models, volume is proportional to the square of radial distance.

\section{ACKNOWLEDGEMENTS}

We thank C. Oldenburg and K. Karasaki for their critical reviews. This work is part of the GEO-SEQ project, which is supported by the U.S. Department of Energy through the National Energy Technology Laboratory (NETL) under Contract No. DE-AC03-76SF00098.

\section{REFERENCES}

1. Pruess, K., Oldenburg, C., and Moridis, G. (1999). Rep. LBNL-43134, Lawrence Berkeley National Laboratory, Berkeley, CA.

2. Pruess, K. and García, J. (2002). Environmental Geology, 42, 282-295.

3. Xu, T., Apps, J.A., and Pruess, K. (2002). Rep. LBNL-50089, Lawrence Berkeley National Laboratory, Berkeley, CA.

4. Hovorka, S.D., Doughty, C., Knox, P.R., Green, C.T., Pruess, K., and Benson, S.M. (2001). Evaluation of brine-bearing sands of the Frio formation, upper Texas gulf coast for geological sequestration of $\mathrm{CO}_{2}$, First National Conference on Carbon Sequestration, May 14-17, Washington DC, National Energy Technology Laboratory.

5. Doughty, C., Pruess, K., Benson, S.M., Hovorka, S.D., Knox, P.R., and Green, C.T. (2001). Capacity Investigation of Brine-Bearing Sands of the Frio Formation for Geologic Sequestration of $\mathrm{CO}_{2}$, First National Conference on Carbon Sequestration, May 14-17, Washington DC, National Energy Technology Laboratory.

6. Buckley, S.E. and Leverett, M.C. (1942). Trans. Am. Inst. Min. Metall. Eng., 146, 107-116.

7. Pruess, K., T. Xu, J. Apps, and J. Garcia. (2001). Numerical modeling of aquifer disposal of $\mathrm{CO}_{2}$, Society of Petroleum Engineers, SPE/EPA/DOE Exploration and Production Environmental Conference, San Antonio, TX, 26-28 February.

8. van der Meer, L.G.H.. (1995). Energy Conservation and Management, 36, 6-9, 513-518. 